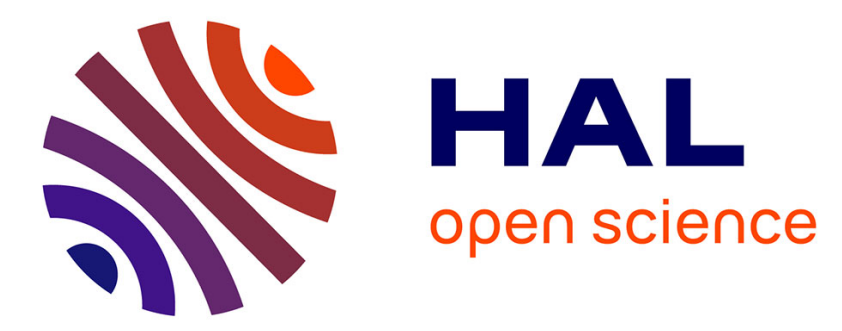

\title{
ELECTROREFLECTANCE AND BAND STRUCTURE OF ZnSiAs2-xPx ALLOYS
}

J. Gallay, A. Deschanvres, Sophie Gaillard, C. Alibert

\section{To cite this version:}

J. Gallay, A. Deschanvres, Sophie Gaillard, C. Alibert. ELECTROREFLECTANCE AND BAND STRUCTURE OF ZnSiAs2-xPx ALLOYS. Journal de Physique Colloques, 1975, 36 (C3), pp.C3-123-

C3-127. 10.1051/jphyscol:1975323 . jpa-00216293

\section{HAL Id: jpa-00216293 https://hal.science/jpa-00216293}

Submitted on 1 Jan 1975

HAL is a multi-disciplinary open access archive for the deposit and dissemination of scientific research documents, whether they are published or not. The documents may come from teaching and research institutions in France or abroad, or from public or private research centers.
L'archive ouverte pluridisciplinaire HAL, est destinée au dépôt et à la diffusion de documents scientifiques de niveau recherche, publiés ou non, émanant des établissements d'enseignement et de recherche français ou étrangers, des laboratoires publics ou privés. 


\title{
ELECTROREFLECTANCE AND BAND STRUCTURE OF $\mathrm{ZnSiAs}_{2-x} \mathbf{P}_{x}$ ALLOYS
}

\author{
J. GALLAY and A. DESCHANVRES \\ Equipe de Cristallographie et Chimie du Solide ERA no 305 \\ Université de Caen, F 14032 Caen, France
}

S. GAILLARD and C. ALIBERT

Centre d'Etudes d'Electronique des Solides (*)

U. S. T. L., F 34060 Montpellier Cédex, France

\begin{abstract}
Résumé. - L'étude de la solution solide $\mathrm{ZnSiAs}_{2-x} \mathrm{P}_{x}$ montre que la variation des paramètres $a$ et $c$ en fonction de la composition suit la loi de Végard. L'étude de cette solution solide par électroréflectance, à température ambiante, a permis d'établir l'évolution des transitions directes en fonction de la composition et de déterminer le gap de $\mathrm{ZnSiP}_{2}: \Gamma_{7} \rightarrow \Gamma_{6}=3,42 \mathrm{eV}$. Les valeurs expérimentales du champ cristallin et de l'éclatement spin-orbite obtenues à partir du modèle quasi cubique sont en bon accord avec les valeurs théoriques.
\end{abstract}

\begin{abstract}
We verify the Vegard law for $\mathrm{ZnSiAs}_{2-x} \mathrm{P}_{x}$ solid solution. We follow by electroreflectance the $\Gamma_{15} \rightarrow \Gamma_{1}$ transitions in the entire range of composition and give the direct threshold $\Gamma_{7} \rightarrow \Gamma_{6}=3.42 \mathrm{eV}$ for $\mathrm{ZnSiP}_{2}$. From the quasicubic model we obtain the crystal field and the spinorbit splitting which are comparcd with theory.
\end{abstract}

For the II-IV-V $\mathrm{V}_{2}$ chalcopyrite semiconductors, experimental [1] and theoretical [2] results give two models of band structure. They may have direct energy gap derived from the zincblende $\Gamma_{15} \rightarrow \Gamma_{1}$ levels or a pseudodirect gap : in the last case the minimum of the conduction band $\Gamma_{3}$ derives from the $\mathrm{X}_{1}(0,0,2 \pi / a)$ point of the zincblende. $\mathrm{ZnSiAs}_{2}$ and $\mathrm{ZnSiP}_{2}$ have such a pseudodirect gap [1].

The direct edge of $\mathrm{ZnSiAs}_{2}$ has been extensively studied [3-5]. In the case of $\mathrm{ZnSiP}_{2}$ the nature of the fundamental edge is not well understood. Several authors [6-8] have studied this edge by different technics; the experimental values of the direct gap are not in good agreement. Particularly recent electroreflectance (E. R.) measurements by J. L. Shay et al. [9] show an interesting result the structure observed near $3 \mathrm{eV}$ cannot derive from a $\Gamma_{15} \rightarrow \Gamma_{1}$ transition and the direct transition seems to be at higher energy.

We have performed E. R. experiments on the $\mathrm{ZnSiAs}_{2-x} \mathrm{P}_{x}$ solid solution which allowed us to follow continuously the direct transitions $\Gamma_{15} \rightarrow \Gamma_{1}$ from $\mathrm{ZnSiAs}_{2}$ to $\mathrm{ZnSiP}_{2}$. At our knowledge the only optical results previously reported on this compound were based upon absorption measurements [10] which cannot give in this case information about such a transition.

$\mathrm{ZnSiAs}_{2-{ }_{x}} \mathrm{P}_{x}$ crystals of $0 \leqslant x \leqslant 2$ were obtained by vapour phase transport from $5 \mathrm{~N}$ elements with stoechiometric proportions. Mercuric chloride of concen-

(*) Associé au C. N. R. S. tration varying from 1 to $3 \mathrm{mg} / \mathrm{cm}^{3}$ was used as silicon carrier. The quartz ampule of $15 \mathrm{~cm}$ long and $16 \mathrm{~mm}$ in diameter was put in a linear temperature gradient $\left(1120^{\circ} \mathrm{C}-1050^{\circ} \mathrm{C}\right.$ ). The temperature setting up stands at $530^{\circ} \mathrm{C}$ to obtain $\mathrm{ZnP}_{2}$ and goes to higher temperature with a slow heating rate of $20^{\circ} \mathrm{C}$ per hour in order to ensure the complete reaction of the group $\mathrm{V}$ elements.

The transport duration is included between 4 and 8 days. Mixed crystals were about $3 \times 2 \times 0.5 \mathrm{~mm}^{3}$, they were smaller than $\mathrm{ZnSiAs}_{2}$ crystals $\left(4 \times 3 \times 1 \mathrm{~mm}^{3}\right)$ and $\mathrm{ZnSiP}_{2}$ crystals $\left(5 \times 2 \times 0.5 \mathrm{~mm}^{3}\right)$. The crystals are homogeneous within the electron microprobe uncertainty which is typically 0.02 atomic fraction. In the ampule according to the temperature deposition we obtain different crystals. The phosphorus rich alloys are grown in the coldest part of the tube.

The habit of growth of the $\mathrm{ZnSiAs}_{2-x} \mathrm{P}_{x}$ solid solution is the chalcopyrite one. The crystals are lengthened along the 111 axis and have natural facets (112) and $(0 \overline{1})$. The solid solution lattice constants $a$ and $c$ (Table I) were determined by classical diffractometry measurements using $\mathrm{Cu}_{\mathrm{k} \alpha} \mathrm{X}$ ray. Their variation versus $x$ is reported in figure 1 . They are consistent with the Vegard law which does not agree with previous results [11]. We can notice in figure 2 the small linear variation of the $c / a$ ratio.

Electroreflectance spectra have been obtained at $300 \mathrm{~K}$ by the electrolyte method (KCL N/10) with linearly polarized light. Our experimental set up has been described elsewhere [12]. Light reflecting faces 


\section{TABLE I}

Lattice parameters of the solid solution $\mathrm{ZnSiAs}_{2-x} \mathrm{P}_{x}$

\begin{tabular}{|c|c|c|c|}
\hline & $a(\AA)$ & $c(\AA)$ & $c / a$ \\
\hline $\mathrm{ZnSiAs}_{2}$ & $5.613 \pm 0.001$ & $10.887 \pm 0.002$ & 1.9 \\
\hline $\mathrm{ZnSiAs}_{1.50} \mathbf{P}_{0.50}$ & $5.559 \pm 0.001$ & $10.778 \pm 0.002$ & 1.939 \\
\hline $\mathrm{iAs}_{1.25} \mathrm{P}_{0.75}$ & $5.531 \pm 0.001$ & $10.714 \pm 0.002$ & 1.937 \\
\hline SiAc & $5.506 \pm 0.001$ & $10.658 \pm 0.003$ & 1.936 \\
\hline iAs 0.6 & $5.475+0.002$ & $10.590+0.005$ & 1.934 \\
\hline $\mathrm{ZnSiP}_{2}$ & $5.399+0.001$ & $10.435 \doteq 0.002$ & 1.933 \\
\hline
\end{tabular}

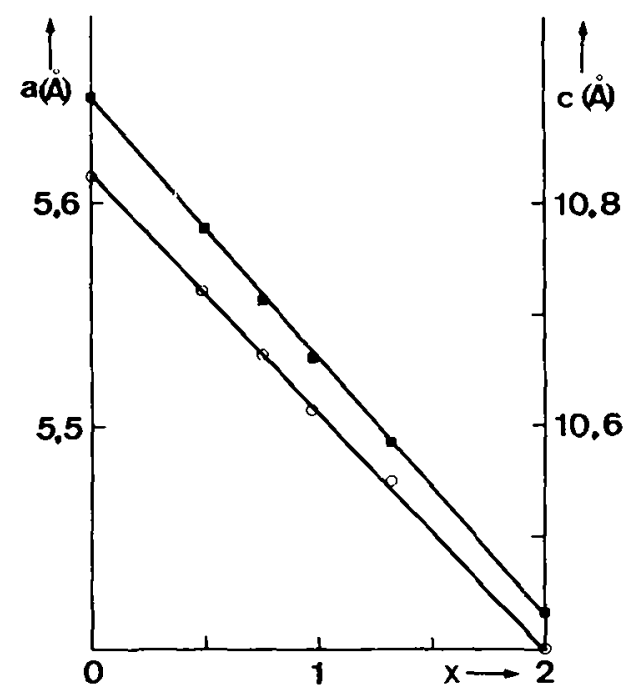

FIG. 1. - Lattice parameters $a$ and $c$ of $\mathrm{ZnSiAs}_{2-x} \mathrm{P}_{x}$.

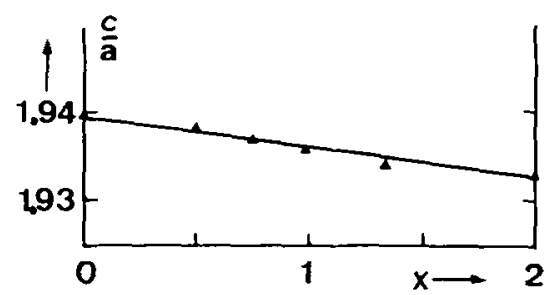

FIG. 2. $-c / a$ ratio variation versus $x$ of $\mathrm{ZnSiAs}_{2-x} \mathrm{P}_{x}$.

were natural facets $(\overline{1} \overline{1} 2)$ or $(0 \overline{1} 1)$ polished with diamond paste. At the rear face an ohmic contact was taken with tin or indium.

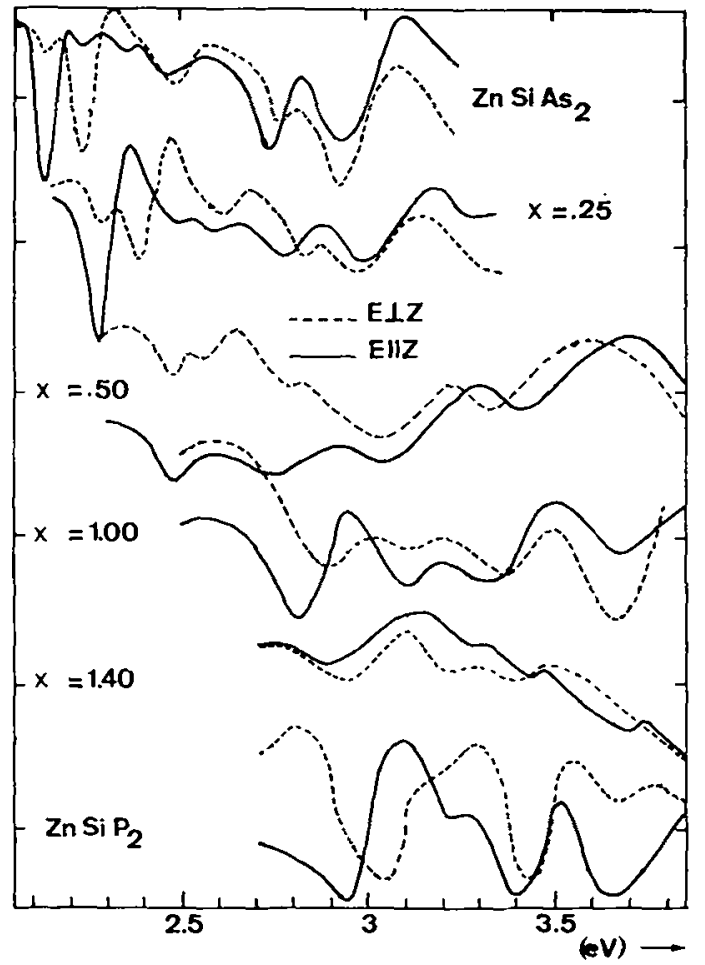

FIG. 3. - Room tempcrature E. R. spectra of $\mathrm{ZnSiAs}_{2-x} \mathbf{P}_{x}$. Alloys for light polarized relative to the optic axis.

Typical E. R. spectra are reported on figure 3 for different concentrations. The $\mathrm{ZnSiAs}_{2}$ and $\mathrm{ZnSiP}_{2}$ spectra are similar to those previously reported by Shay et al. [3-9]. When the phosphorus concentration is more important than the arsenic one, an apparent modification of the selection rules appears for the first structure in the E. R. spectra; this effect has been observed by Shay et al. [9] in $\mathrm{ZnSiP}_{2}$ and can be explained by a pseudodirect transitions mixing. When the arsenic concentration is more important than the phosphorus one the three transitions $(\mathrm{A}, \mathrm{B}, \mathrm{C})$ associated with the direct threshold $\Gamma_{15} \rightarrow \Gamma_{1}$ are well resolved with the same selection rule than $\mathrm{ZnSiAs}_{2}$. The $\mathrm{A}, \mathrm{B}, \mathrm{C}$ transitions observed are given in table II. Within the experimental uncertainty we can give a linear interpretation of the variation vs the concentration $x$ of the direct transition (Fig. 4). We can notice

TABLE II

Energies transitions associated with the zincblende $\Gamma_{15} \rightarrow \Gamma_{1}$ levels of $\mathrm{ZnSiAs}_{2-x} \mathrm{P}_{x}$

$\begin{array}{ll}\mathrm{ZnSiAs}_{2} & 2.14 \pm 0.02 \\ \mathrm{ZnSiAs}_{1.90} \mathrm{P}_{0.10} & 2.21 \pm 0.02 \\ \mathrm{ZnSiAs}_{1.75} \mathrm{P}_{0.25} & 2.31 \pm 0.02 \\ \mathrm{ZnSiAs}_{1.68} \mathrm{P}_{0.32} & 2.36 \pm 0.02 \\ \mathrm{ZnSiAs}_{1.50} \mathrm{P}_{0.50} & 2.47 \pm 0.02 \\ \mathrm{ZnSiAsP}_{\mathrm{ZnSiAs}} & 2.78 \pm 0.02 \\ \mathrm{ZnSiP}_{0.60} \mathrm{P}_{1.40} & 3.04 \pm 0.04 \\ & 3.42 \pm 0.02\end{array}$

$\mathrm{ZnSiAs}_{2}$

$\mathrm{ZnSiAs}_{1.90} \mathrm{P}_{0.10}$

ZnSiAs $1.50 \mathrm{P}_{0.50}$

ZnSiAsP

$\mathrm{ZnSiP}_{2}$
$\mathrm{A} \|(1) \mathrm{eV}$
$2.14 \pm 0.02$
$2.21 \pm 0.02$
$2.36 \pm 0.02$
$2.47 \pm 0.02$
$3.04 \pm 0.04$
$3.42 \pm 0.02$

$$
\begin{gathered}
\mathrm{B} \perp \mathrm{eV} \\
2.24 \pm 0.02 \\
2.31 \pm 0.02 \\
2.40 \pm 0.02 \\
2.46 \pm 0.02 \\
2.57 \pm 0.02 \\
2.88 \pm 0.03 \\
3.17 \pm 0.04
\end{gathered}
$$

$\mathrm{C} \perp(\|) \mathrm{eV}$

$2.49 \pm 0.03$

$2.54 \pm 0.03$

$2.62 \pm 0.03$

$2.67 \pm 0.03$

$2.77 \pm 0.03$

$3.04 \pm 0.03$

$3.28 \pm 0.04$

$3.63 \pm 0.03$ 


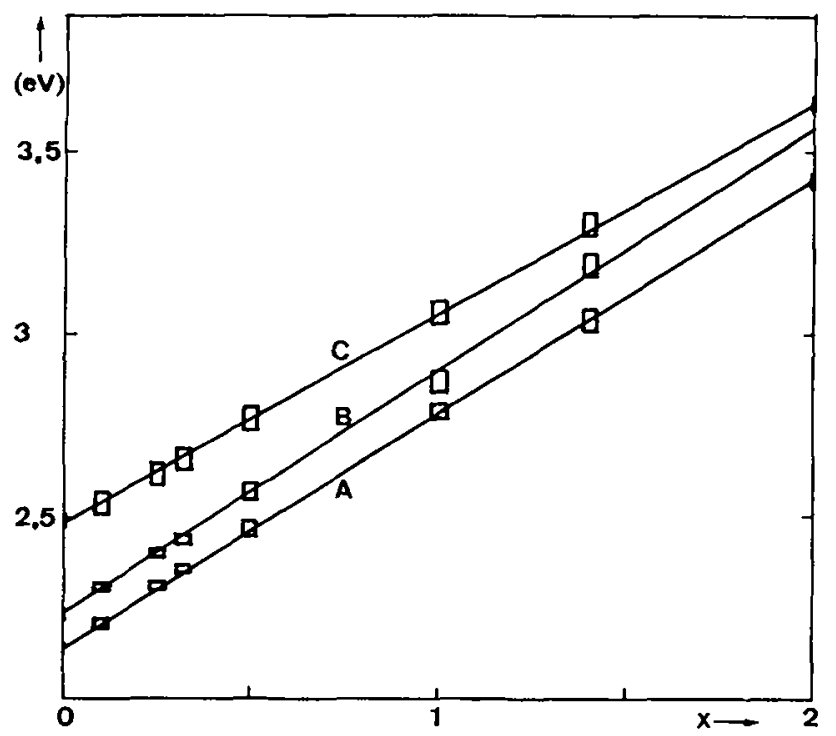

FIG. 4. - Energies of the $\Gamma_{15} \rightarrow \Gamma_{1}$ transitions vs composition $x$ of $\mathrm{ZnSiAs}_{2-x} \mathrm{P}_{x}$ at room temperature.

for the first time that the value of the $\Gamma_{7} \rightarrow \Gamma_{6}$ direct threshold of $\mathrm{ZnSiP}_{2}$ is $3.42 \mathrm{eV}$ at $300 \mathrm{~K}$. This value is in good agreement with the mean energy gap theoretically obtained by L. P. Pasemann [13] (3.9 eV at $0 \mathrm{~K}$ ) and is $1 \mathrm{eV}$ at less above the previous experimental results [6-9]. The B, C transitions become nearer when $x$ increases and are not separable for $\mathrm{ZnSiP}_{2}$.

In the II-IV-V $V_{2}$ compounds J. E. Rowe and J. L. Shay [14] have shown that the quasicubic model can explain the splitting of the $\Gamma_{15}$ zincblende valence band under the combined action of the crystal field $\Delta_{\mathrm{cf}}$ and the spin-orbit splitting $\Delta_{\text {so }}$ (Fig. 5). The Hopfield theory [15] allows the calculation of $\Delta_{\mathrm{cf}}$ and $\Delta_{\mathrm{so}}$ from the $A, B, C$ transition energies

$$
\begin{aligned}
E_{1}=E_{\mathrm{A}}-E_{\mathrm{B}}=\frac{1}{2}\left(\Delta_{\mathrm{So}}+\Delta_{\mathrm{ef}}\right)-\frac{1}{2} \times & \\
\times & {\left[\left(\Delta_{\mathrm{SO}}+\Delta_{\mathrm{cf}}\right)^{2}-\frac{8}{3} \Delta_{\mathrm{so}} \Delta_{\mathrm{cf}}\right]^{1 / 2} }
\end{aligned}
$$

$$
\begin{aligned}
E_{2}=E_{\mathrm{C}}-E_{\mathrm{B}}=\frac{1}{2} & \left(\Delta_{\mathrm{SO}}+\Delta_{\mathrm{cf}}\right)+\frac{1}{2} \times \\
\times & {\left[\left(\Delta_{\mathrm{SO}}+\Delta_{\mathrm{cf}}\right)^{2}-\frac{8}{3} \Delta_{\mathrm{SO}} \Delta_{\mathrm{cf}}\right]^{1 / 2} . }
\end{aligned}
$$

These relations have allowed us (Fig. 6) to determine from our data the variations vs the concentration $x$ of $\Delta_{\text {cf }}$ (Fig. 7) and $\Delta_{\text {so }}$ (Fig. 8). For $\mathrm{ZnSiP}_{2}$ the values of the band $\mathrm{C}$ transition energies have been determined by extrapolation of their linear variation (Fig. 4).

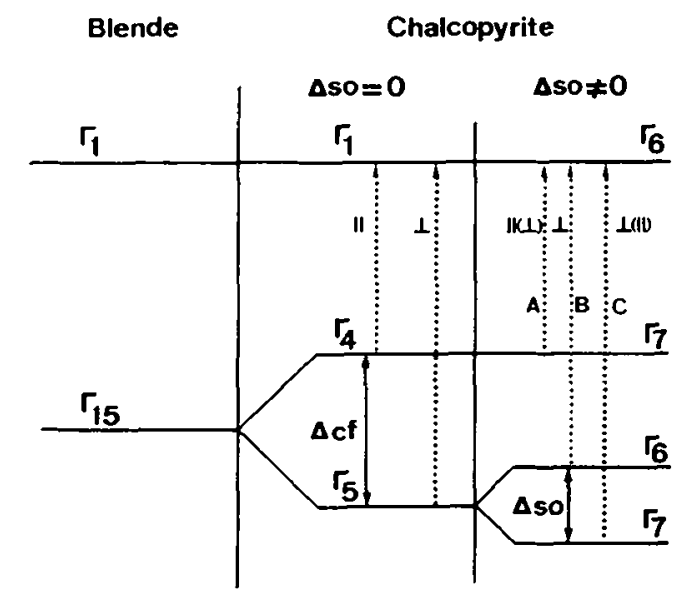

Fig. 5. -- Band structure and selection rules at $k=(000)$ in zincblende and chalcopyrite for light polarized relative to the optic axis. Polarizations in parentheses are allowed only when spin orbit interaction is included.

The theoretical variation of $\Delta_{\mathrm{cf}}$ is given by

$$
\Delta_{\mathrm{cf}}=\frac{3}{2} b\left(2-\frac{c}{a}\right)
$$

where $b$ is the deformation potential describing the splitting of the valence bands in the zincblende under uniaxial stress. From the $\mathrm{ZnSiAs}_{2}$ results we have taken

\begin{tabular}{|c|c|c|c|c|}
\hline & $\begin{array}{c}\Delta_{\text {so }} \\
\text { (Hopfield) } \\
\text { eV }\end{array}$ & $\Delta_{\mathrm{so}\left(f_{1}\right)}$ & $\begin{array}{c}\Delta_{\mathrm{cf}} \\
\text { (Hopfield) } \\
\mathrm{eV}\end{array}$ & $\Delta_{\mathrm{cf}}=\frac{3}{2} b\left(2-\frac{c}{a}\right)$ \\
\hline $\mathrm{ZnSiAs}_{2}$ & $\overline{0.28}$ & $\overline{0.29}$ & $-\overline{0.13}$ & $-0.13(b=-1.4)$ \\
\hline $\mathrm{ZnSiAs}_{2}$ (ref. [3]) & 0.28 & 0.29 & -0.13 & $-0.16(b=-1.8)$ \\
\hline $\mathrm{ZnSiAs}_{1.90} \mathrm{P}_{0.10}$ & 0.26 & 0.28 & -0.13 & \\
\hline $\mathrm{ZnSiAs}_{1.75} \mathrm{P}_{0.25}$ & 0.25 & 0.27 & -0.12 & \\
\hline $\mathrm{ZnSiAs}_{1.68} \mathrm{P}_{0.32}$ & 0.24 & 0.26 & -0.13 & \\
\hline $\mathrm{ZnSiAs}_{1.50} \mathrm{P}_{0.50}$ & 0.23 & 0.24 & -0.13 & \\
\hline ZnSiAsP & 0.19 & 0.18 & -0.13 & \\
\hline $\mathrm{ZnSiAs}_{0.60} \mathrm{P}_{1.40}$ & 0.14 & 0.14 & -0.16 & \\
\hline $\mathrm{ZnSiP}_{2}$ & 0.09 & 0.07 & -0.16 & $-0.14(b=-1.4)$ \\
\hline $\mathrm{ZnSiP}_{2}$ (ref. [18]) & 0.07 & 0.07 & -0.13 & $-0.14(b=-1.4)$ \\
\hline
\end{tabular}
$b=-1.4 \mathrm{eV}$. This experimental value is in good agreement with those of GaAs $(-1.75 \mathrm{eV})[15]$ and

\section{TABLE III}

Theoretical and experimental values of the spin orbit splitting and the crystal field of $\mathrm{ZnSiAs}_{2-x} \mathrm{P}_{x}$ alloys 


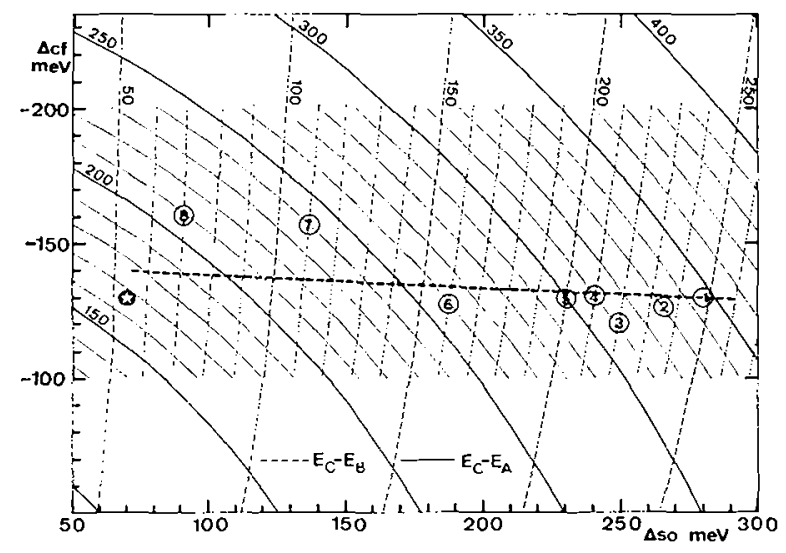

FrG. 6. - Graphic determination of $\Delta_{\text {so }}$ and $\Delta_{c t}$ from the A, B, C transitions energies of $\operatorname{ZnSiAs}_{2-x} \mathbf{P}_{x}$ for: $1, x=0$; $2, x=0.1 ; 3, x=0.25 ; 4, x=0.32 ; 5, x=0.5 ; 6, x=1$; $7, x=1.4 ; 8, x=2$. $\odot$. Babonas value [18].

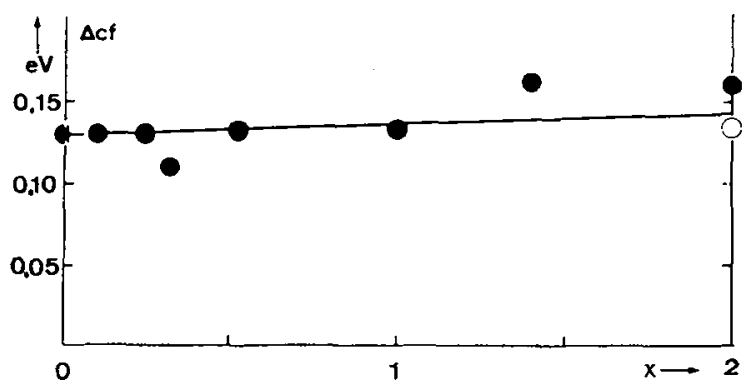

Frg. 7. - Variation of the crystal field splitting vs $x$ of $\mathbf{Z n S i A s}_{2-x} \mathbf{P}_{x}$ full line theory with $b=-1.4 \mathrm{eV}$. Our experimental values. O G. Babonas value [18]. $\star$ J. L. Shay value [13].

GaP $(-1.5 \mathrm{eV})$ [17]. This value is used in the entire range of composition of the solid solution and gives for $\mathrm{ZnSiP}_{2} \Delta_{\mathrm{cf}}=-0.13 \mathrm{eV}$ which is the result obtained by G. Babonas [18] from wavelength modulated absorption measurements. The theoretical variation of $\Delta_{\text {so }}$ is obtain from the $\mathrm{K}$. Hübner model [19]

$$
\begin{aligned}
\Delta_{\mathrm{SO}}=\frac{1-f_{\mathrm{i}}(x)}{2}\left[\frac{\Delta_{\mathrm{Zn}}+\Delta_{\mathrm{Si}}}{2}\right]+ \\
\quad+\frac{1+f_{\mathrm{i}}(x)}{4}\left[\Delta_{\mathrm{As}}(2-x)+\Delta_{\mathrm{P}} x\right]
\end{aligned}
$$

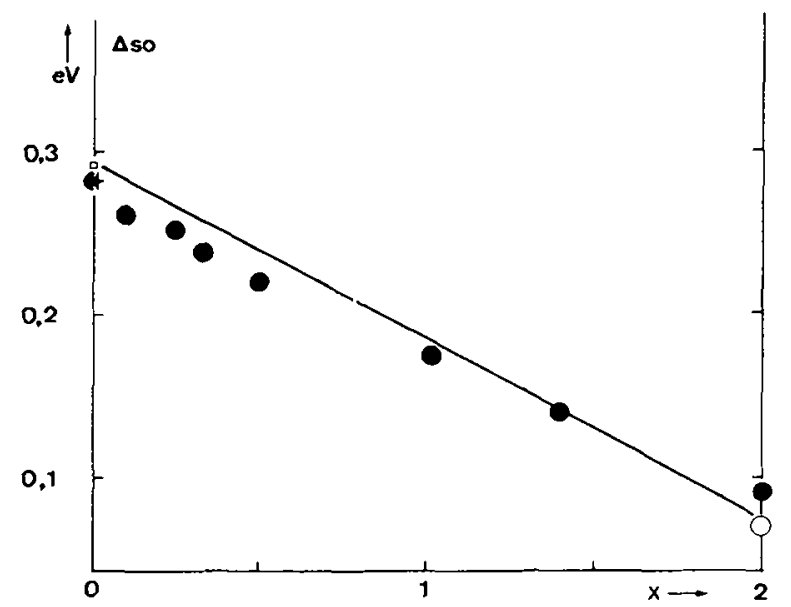

FIG. 8. - Variation of the spin orbit splitting versus $x$ of $\mathrm{ZnSiAs}_{2-x} \mathrm{P}_{x}$ full line theoretical variation. Our experimental values. $O$ G. Babonas value [18]. ^ J. L. Shay value [13]

$f_{\mathrm{i}}(x)$ is the mean ionicity of the chemical bound of the compound. We have taken a linear law for $f_{i}(x)$ which gives the mean ionicity of $\mathrm{ZnSiAs}_{2}$ and $\mathrm{ZnSiP}_{2}$ [20]

$$
f_{\mathrm{i}}(x)=0.279+0.033 x
$$

$\frac{1-f_{\mathrm{i}}(x)}{2}$ is the valence electron probability to be found $\frac{1+f_{\mathrm{i}}(x)}{4}$ is the valence electron probability to be found at the $\mathrm{V}$-atom in the unit cell,

$\Delta \mathrm{As}, \Delta \mathrm{Zn}, \Delta \mathrm{Si}, \Delta \mathrm{P}$ are the atomic spin orbit splitting given by F. Herman et al. [21].

On figures 7 and 8 we have reported the theoretical variation of $\Delta_{\mathrm{cf}}$ and $\Delta_{\text {so }}$ which are in good agreement with their experimental determination.

In conclusion we have reported that the variation vs $x$ of the $\mathrm{ZnSiAs}_{2-x} \mathrm{P}_{x}$ lattice parameters $a$ and $c$ follows the Vegard law. By following continuously the $\Gamma_{15} \rightarrow \Gamma_{1}$ transitions from $\mathrm{ZnSiAs}_{2}$ to $\mathrm{ZnSiP}_{2}$ we have shown that the direct gap of $\mathrm{ZnSiP}_{2}$ associated to the $\Gamma_{7} \rightarrow \Gamma_{6}$ levels is $3.42 \mathrm{eV}$. We have observed that the valence band splittings are explained by the quasicubic model and are in good agreement with theory.

\section{References}

[1] For a recent review, see SHILEIKA, A., Surf. Sci. 37 (1973) 730.

[2] Gokyunova, N. A., Poplavnol, A. S., Polycalov, Yu. I. and Chaldyshev, V. A., Phys. Stat. Sol. 39 (1970) 9.

[3] Shay, J. L., Buehler, E. and Wernick, J. H., Phys. Rev. B 3 (1971) 2004.

[4] Kwav, C. C. Y. and Woolley, J. C., Can.J. Phys. 48 (1970) 2085.

[5] Kwan, C. C. Y. and Woolley, J. C., Appl. Phys. Lett. 18 (1971) 520.
[6] Vaipolin, A. A., Goryunova, N. A., Osmanov, E. O. Rud, Yu. V. and TretYakov, D. N., Dokl. Akad. Nauk SSSR 154 (1964) 1116.

[7] Goryunova, N. A., Grigoryan, S. S. and Zllatkin, L. B. Izv. Akad. Nauk SSSR, Neorg. Mater. 2 (1966) 2125.

[8] Bendorius, R., Prochukhan, V. D. and Sileika, A., Phys Stat. Sol. (b) 53 (1972) 745.

[9] Shay, J. L., Tell, B., Buehler, E. and Wernck, J. H., Phys. Rev. Lett. 30 (1973) 983.

[10] Clark, W. C. and Stroud, R. F., J. Phys. C (Solid State Phys.) 6 (1973) 2184. 
(11) Spring-Thorpe, A. J. and Pampin, B. R., J. Crystal Growth, 3 (1968) 313.

[12] Alibirt, C., Bordure, G., Lnugier, A. and Chevallier, J. Phys. Rev. B 6(1972) 1301.

[13] Pasemann, L., Phys. Stat. Sol. (b) 56 (1973) K 69.

[14] Rowe, J. E. and Shay, J. L., Phys. Rev. B 3 (1971) 451.

[15] Hopfield, J. J., J. Phys. Chem. Solids 15 (1960) 97.

[16] Gavani, A. and Cakdona, M., Phys. Rev. B 1 (1970) 672.
117) WILEY, J. D., Solid State Commun. 8 (1970) 1865.

[18] Babonas, G., Ambrazeviclus, G., Grigoreva, V. S., Niviera, V. and Shileika, A., Phys. Stat. Sol. (b) 62 (1974) 327.

[19] Hunner, K. and Unger, K., Phys. Stat. Sol. (b) 50 (1972) $\mathrm{K} 105$.

[20] Kremer, K. (to be published).

[21] Herman, F., Kuglin, C. D., Cuff, K. F. and Kortum, R. L., Phys. Rev. Lett. 11 (1963) 541. 